\title{
What should the blood pressure be in patients with chronic kidney disease?
}

\author{
Wilbert S. Aronow \\ Division of Cardiology, Department of Medicine, Westchester Medical Center/New York Medical College, Valhalla, NY, USA \\ Correspondence to: Wilbert S. Aronow, MD, FACC, FAHA. Professor of Medicine, Cardiology Division, New York Medical College, Macy Pavilion, \\ Room 138, Valhalla, NY 10595, USA. Email: wsaronow@aol.com.
}

Submitted Jan 08, 2017. Accepted for publication Jan 05, 2017.

doi: $10.21037 / \mathrm{atm} .2017 .01 .15$

View this article at: http://dx.doi.org/10.21037/atm.2017.01.15

The Modification of Diet in Renal Disease (MDRD) Study randomized 840 patients, with nondiabetic stage 3 to 4 chronic kidney disease to a blood pressure of less than $140 / 90 \mathrm{mmHg}$ or to a blood pressure of $125 / 75 \mathrm{mmHg}$ $(1,2)$. The blood pressures achieved in this study were $133 / 80 \mathrm{mmHg}$ versus $126 / 77 \mathrm{mmHg}$. The mean followup was 2.2 years. This study did not show a difference in death and in kidney failure between the 2 blood pressure groups. However, this study showed that in patients with proteinuria greater than 1,000 $\mathrm{mg}$ per day, the lower blood pressure group had a significant slower rate of decline in glomerular filtration rate $(1,2)$.

The Ramipril Efficacy in Nephropathy (REIN-2) trial randomized 338 patients with nondiabetic stage 3 to 4 chronic kidney disease to a blood pressure of less than $140 / 90 \mathrm{mmHg}$ or to a blood pressure of less than $130 / 80 \mathrm{mmHg}$ (3). The blood pressures achieved in this study were 134/82 $\mathrm{mmHg}$ versus $130 / 80 \mathrm{mmHg}$. The median follow-up was 1.6 years. This study did not show a difference in death and in kidney failure between the 2 blood pressure groups (3).

The African American Study of Kidney Disease (AASK) trial randomized 1,094 patients with nondiabetic hypertensive stage 3 chronic kidney disease to a blood pressure of less than $140 / 90 \mathrm{mmHg}$ or to a blood pressure of $125 / 75 \mathrm{mmHg}(4,5)$. The blood pressures achieved in this study were $141 / 86$ versus $130 / 78 \mathrm{mmHg}$. The median follow-up was 3.8 years. This study did not show a difference in death, end-stage renal disease, or a reduction in glomerular filtration rate of $50 \%$ or more between the 2 blood pressure groups (4). However, a subanalysis showed a reduction in this primary endpoint in patients with proteinuria with a protein-to-creatinine ratio of more than $0.22(5)$.

A meta-analysis of 2,272 patients with nondiabetic chronic kidney disease in the AASK, REIN-2, and MDRD studies found that the lower blood pressure achieved in these 3 trials of $126-130 / 77-80 \mathrm{mmHg}$ did not improve clinical outcomes (6). However, this meta-analysis suggested that the lower blood pressure target may be beneficial in patients with chronic kidney disease with proteinuria greater than 300 to $1,000 \mathrm{mg}$ daily (6).

On the basis of the available data, the International Society of Nephrology 2012 guidelines for treatment of blood pressure in patients with non-dialysis-dependent chronic kidney disease state that hypertensive patients with chronic kidney disease and albuminuria less than $30 \mathrm{mg}$ per 24 hours should have their blood pressure lowered to less than $140 / 90 \mathrm{mmHg}(7,8)$. If albuminuria greater than $30 \mathrm{mg}$ per 24 hours is present, the blood pressure may be lowered to less than $130 \mathrm{~mm} / 80 \mathrm{mmHg}$ with a class II D indication $(7,8)$.

A meta-analysis reported in 2013 of 11 randomized trials in 9287 patients with chronic kidney disease and 1,264 kidney failure events showed that intensive blood pressure lowering reduced the incidence of kidney failure $27 \%$ but not in patients who did not have baseline proteinuria (9). Another meta-analysis reported in 2013 included 26 randomized trials with 30,295 patients with chronic kidney disease (10). This study showed that compared with placebo, blood pressure lowering reduced the incidence of major cardiovascular events by approximately a sixth per $5 \mathrm{mmHg}$ reduction in systolic blood pressure (10).

A meta-analysis reported in 2016 included 19 randomized 
trials of 44,989 patients with and without chronic kidney disease in whom 2496 major cardiovascular events occurred during a mean follow-up of 3.8 years (11). Compared to a blood pressure achieved of $140 / 81$, more intensive blood pressure lowering to an achieved blood pressure of $133 / 76 \mathrm{mmHg}$ reduced major cardiovascular events $14 \%$. Absolute reductions in major cardiovascular events were greatest in trials in which all enrolled patients had vascular disease, chronic kidney disease, or diabetes mellitus (11).

The most important randomized, antihypertensive clinical trial comparing a systolic blood pressure goal of less than $120 \mathrm{mmHg}$ with a systolic blood pressure goal of less than $140 \mathrm{mmHg}$ which included patients with chronic kidney disease is the Systolic Blood Pressure Intervention Trial (SPRINT) $(12,13)$. This trial included 9,361 patients aged 50 years and older with a systolic blood pressure of $130 \mathrm{mmHg}$ or higher and an increased cardiovascular risk but without diabetes mellitus, prior stroke, heart failure, or a left ventricular ejection fraction below $35 \%$. The mean age was 67.9 years, $28.3 \%$ of patients were aged 75 years and older, and $28.4 \%$ of patients had chronic kidney disease with a baseline estimated glomerular filtration rate between 20 to $59 \mathrm{~mL} / \mathrm{min} / 1.73 \mathrm{~m}^{2}$ Automated blood pressures were obtained in this study. The mean achieved systolic blood pressures at 1 year were $121.4 \mathrm{mmHg}$ in the intensive treatment group versus $136.2 \mathrm{mmHg}$ in the standard treatment group. The median follow-up was 3.26 years. The primary composite endpoint was cardiovascular death, myocardial infarction, other acute coronary syndromes, heart failure, or stroke. At follow-up, intensive treatment of blood pressure reduced the primary outcome $25 \%$ and all-cause mortality $27 \%$ in the entire group (12) and the primary outcome $34 \%$ and all-cause mortality $33 \%$ in the group aged 75 years and older (13). In the entire group of patients with chronic kidney disease, all-cause mortality was reduced $27 \%$ from $7.22 \%$ with standard blood pressure treatment to $5.26 \%$ with intensive blood pressure treatment (12). The composite renal outcome of first occurrence of a reduction in estimated glomerular filtration rate of $50 \%$ or more, long-term dialysis, or kidney transplantation was $1.1 \%$ in both blood pressure treatment groups. Intensive blood pressure treatment was also beneficial in patients with chronic kidney disease who were aged 75 years and older including those with frailty or the slowest gait speed (13).

On the basis of the data from SPRINT, the 2016 Canadian hypertension guidelines recommended lowering the systolic blood pressure to $120 \mathrm{mmHg}$ or lower in selected high-risk patients such as those with chronic kidney disease with an estimated glomerular filtration rate between 20 to $59 \mathrm{~mL} / \mathrm{min} / 1.73 \mathrm{~m}^{2}(14,15)$. Automated blood pressures must be obtained in these patients. I concur with automated blood pressure measurements since they are more accurate. On the basis of the current available data, I favor lowering the blood pressure in patients with chronic kidney disease to less than $130 / 80 \mathrm{mmHg}$.

Angiotensin-converting enzyme inhibitors, angiotensin receptor blockers, beta blockers, calcium channel blockers, and thiazide or thiazide-like diuretics are effective in reducing cardiovascular events in patients with hypertension associated with chronic kidney disease $(16,17)$. However, angiotensin-converting enzyme inhibitors or angiotensin receptor blockers are more effective than other antihypertensive drugs in slowing progression of chronic kidney disease with proteinuria $(18,19)$. The combined use of an angiotensin-converting enzyme inhibitor with an angiotensin receptor blocker should be avoided (20).

\section{Acknowledgements}

None.

\section{Footnote}

Conflicts of Interest: The author has no conflicts of interest to declare.

\section{References}

1. Klahr S, Levey AS, Beck GJ, et al. The effects of dietary protein restriction and blood pressure control on the progression of chronic renal disease. N Engl J Med 1994;330:877-84.

2. Lazarus JM, Bourgoignie JJ, Buckalew VM, et al. Achievement and safety of a lower blood pressure goal in chronic renal disease. The Modification of Diet in Renal Disease Study Group. Hypertension 1997;29:641-50.

3. Ruggenenti P, Perna A, Lorigo G, et al. Blood-pressure control for renoprotection in patients with non-diabetic chronic renal disease (REIN-2): multicentre, randomised controlled trial. Lancet 2005;365:939-46.

4. Wright JT Jr, Bakris G, Greene T, et al. Effect of blood pressure lowering and antihypertensive drug class on progression of hypertensive kidney disease: results from the AASK trial. JAMA 2002;288:2421-31.

5. Appel LJ, Wright JT Jr, Greene T, et al. Intensive blood- 
pressure control in hypertensive chronic kidney disease. $\mathrm{N}$ Engl J Med 2010;363:918-29.

6. Upadhyay A, Earley A, Haynes SM, et al. Systematic review: blood pressure target in chronic kidney disease and proteinuria as an effect modifier. Ann Intern Med 2011;154:541-8.

7. Chapter 3: Blood pressure management in CKD ND patients without diabetes mellitus. Kidney Int Suppl (2011) 2012;2:357-62.

8. Chapter 4. Blood pressure management in CKD ND patients with diabetes mellitus. Kidney Int Suppl (2011) 2012;2:363-9.

9. Lv J, Ehteshami P, Sarnak MJ, et al. Effects of intensive blood pressure lowering on the progression of chronic kidney disease: a systematic review and meta-analysis. CMAJ 2013;185:949-57.

10. Blood Pressure Lowering Treatment Trialists' Collaboration, Ninomiya T, Perkovic V, et al. Blood pressure lowering and major cardiovascular events in people with and without chronic kidney disease: meta-analysis of randomised controlled trials. BMJ 2013;347:f5680.

11. Xie X, Atkins E, Lv J, et al. Effects of intensive blood pressure lowering on cardiovascular and renal outcomes: updated systematic review and meta-analysis. Lancet 2016;387:435-43.

12. Wright JT Jr, Williamson JD, Whelton PK, et al. A randomized trial of intensive versus standard bloodpressure control. N Engl J Med 2015;373:2103-16.

13. Williamson JD, Supiano MA, Applegate WB, et al. Intensive vs standard blood pressure control and cardiovascular disease outcomes in adults aged 75 years. A

Cite this article as: Aronow WS. What should the blood pressure be in patients with chronic kidney disease? Ann Transl Med 2017;5(3):48. doi: 10.21037/atm.2017.01.15 randomized clinical trial. JAMA 2016;315:2673-82.

14. Padwal R, Rabi DM, Schiffrin EL. Recommendations for intensive blood pressure lowering in high-risk patients: the Canadian viewpoint. Hypertension 2016;68:3-5.

15. Leung AA, Nerenberg KL, Daskalopoulou SS, et al. Hypertension Canada's 2016 Canadian Hypertension Education Program Guidelines for blood pressure measurement, diagnosis, assessment of risk, prevention, and treatment of hypertension. Can J Cardiol 2016;32:569-88.

16. Aronow WS, Fleg JL, Pepine CJ, et al. ACCF/AHA 2011 expert consensus document on hypertension in the elderly: a report of the American College of Cardiology Foundation Task Force on Clinical Expert Consensus Documents. J Am Coll Cardiol 2011;57:2037-114

17. Law MR, Morris JK, Wald NJ. Use of blood pressure lowering drugs in the prevention of cardiovascular disease: meta-analysis of 147 randomised trials in the context of expectations from prospective epidemiological studies. BMJ 2009;338:b1665.

18. Jafar TH, Schmid CH, Landa M, et al. Angiotensinconverting enzyme inhibitors and progression of nondiabetic renal disease: a meta-analysis of patient-level data. Ann Intern Med 2001;135:73-87.

19. Lewis EJ, Hunsicker LG, Clarke WR, et al. Renoprotectve effect of the angiotensin receptor antagonist irbesaratan in patients with nephropathy due to type 2 diabetes. $\mathrm{N}$ Engl J Med 2001;345:851-60.

20. Fried LF, Emanuele N, Zhang JH, et al. Combined angiotensin inhibition for the treatment of diabetic nephropathy. N Engl J Med 2013;369:1892-903. 